\title{
MODELING COMPUTATIONAL FLUID DYNAMICS OF MULTIPHASE FLOWS IN ELBOW AND T-JUNCTION OF THE MAIN GAS PIPELINE
}

\author{
Yaroslav DOROSHENKO ${ }^{1}$, Julia DOROSHENKO ${ }^{2}$, Vasyl ZAPUKHLIAK ${ }^{3}$, \\ Lyubomyr POBEREZHNY ${ }^{4}$, Pavlo MARUSCHAK ${ }^{5^{*}}$ \\ ${ }^{1-4}$ Dept of Construction and Repair Oil and Gas Pipelines and Storage Facilities, \\ Ivano-Frankivsk National Technical University of Oil and Gas, Ukraine \\ ${ }^{5}$ Dept of Industrial Automation, Ternopil Ivan Pul'uj National Technical University, Ukraine
}

Received 17 December 2016; revised 12 May 2017, 23 September 2017; accepted 24 November 2017

\begin{abstract}
The research was performed in order to obtain the physical picture of the movement of condensed droplets and solid particles in the flow of natural gas in elbows and T-junctions of the linear part of the main gas pipeline. 3D modeling of the elbow and T-junction was performed in the linear part of the gas main, in particular, in places where a complex movement of multiphase flows occurs and changes its direction. In these places also occur swirls, collisions of discrete phases in the pipeline wall, and erosive wear of the pipe wall. Based on Lagrangian approach (Discrete Phase Model DPM), methods of computer modeling were developed to simulate multiphase flow movement in the elbow and T-junction of the linear part of the gas main using software package ANSYS Fluent R17.0 Academic. The mathematical model is based on solving the Navier-Stokes equations, and the equations of continuity and discrete phase movement closed with Launder-Sharma $(k-\varepsilon)$ two-parameter turbulence model with appropriate initial and boundary conditions. In T-junction, we simulated gas movement in the run-pipe, and the passage of the part of flow into the branch. The simulation results were visualized in postprocessor ANSYS Fluent R17.0 Academic and ANSYS CFD-Post R17.0 Academic by building trajectories of the motion of condensed droplets and solid particles in the elbow and T-junction of the linear part of the gas main in the flow of natural gas. The trajectories were painted in colors that match the velocity and diameter of droplets and particles according to the scale of values. After studying the trajectories of discrete phases, the locations of their heavy collision with the pipeline walls were found, as well as the places of turbulence of condensed droplets and solid particles. The velocity of liquid and solid particles was determined, and the impact angles, diameters of condensed droplets and solid particles in the place of collision were found. Such results provide possibilities for a full and comprehensive investigation of erosive wear of the elbow and T-junction of the linear part of the gas main and adjacent sections of the pipeline, and for the assessment of their strength and residual life.
\end{abstract}

Keywords: pipeline, elbow, discrete phase, erosive wear, Lagrange approach, movement trajectory, T-junction.

\section{Introduction}

The linear part of the gas main consists of straight sections, curves of elastic bending, curves of cold and hot bending, T-junctions, and valves. The flow of natural gas in curves of hot bending (bends) and T-junctions is complex. In addition, the gas flow changes its direction. As a result, liquid and solid particles (discrete phase) contained in the flow of natural gas (continuous phase) collide with the pipeline wall, causing the erosive wear of the pipe wall. Erosive wear is one of the factors that reduce the residual life of pipelines. The erosive wear of the pipe wall is especially dangerous for the pipelines that have been operated for more than 35...40 years (Maruschak et al. 2013, 2014, 2016a, 2016b, 2018; Vilkys et al. 2018; Poberezhnyi et al. 2016; Poberezhny et al. 2017; Lytvynenko et al. 2018; Panin et al. 2017). Therefore, a comprehensive study of the erosive wear of the pipe wall in gas mains is particularly relevant.

To fully and comprehensively investigate the erosive wear of elbows and T-junctions of the linear part of a gas main, it is necessary to know the locations of the intensive collision of liquid and solid particles carried by the flow of natural gas (multiphase flows) with the pipeline wall, as well as the velocity and diameter of particles, and impact angles in the place of collision. Until recently, some of

\footnotetext{
${ }^{*}$ Corresponding author. E-mail: maruschak.tu.edu@gmail.com

\# Editor of the TRANSPORT - the manuscript was handled by one of the Associate Editors, who made all decisions related to the manuscript (including the choice of referees and the ultimate decision on the revision and publishing).
} 
that information could be obtained only by experimental studies in the laboratory by visualizing the flow moving in transparent pipes. However, such experiments cannot be performed in real gas mains because:

- it is impossible to visualize gas flow in the gas main;

- the pipes of gas mains are made of steel that prevents visual observation of the flow;

- it is impossible to determine the exact value of the velocity, diameter of the discrete phase at any $3 \mathrm{D}$ point in the gas flow in elbows and T-junctions;

- gas mains are operated under high pressure.

One of the promising areas of solving such problems in the shortest time is the active use of up-to-date computer modeling systems that enable doing both separate calculations and solving problems as a whole. Computer modeling systems for 3D flows of gases and fluids include ANSYS Fluent, ANSYS CFX, Flow Vision, Flow3D, and SolidWorks. With the given software systems, one can perform modeling of three-dimensional flows of gas and fluids with the finite volume method. These software systems allow simulation of stationary and non-stationary multiphase flows of gases and fluids. The use of different models of turbulence and adaptive computational grid allows simulating complex flows and flows with strong turbulence. Such software systems can help explore the dynamics of local resistance to multiphase flows and processing equipment of complex configuration of the inner surface.

Multiphase turbulent gas flows with discrete phases are widespread in different processes of power engineering, chemistry, aviation, and so on. This attracts many researchers to study the processes occuring in such flows.

Many modern scientists deal with computer modeling of multiphase 3D flows in the pipeline fittings using various software systems. Their results confirm that these software systems are an effective tool of getting a physical picture of the movement of multiphase flow of gas in fittings, determining the places of intensive collision of particles with the pipeline wall, and the velocity of the particles.

Abdolkarimi and Mohammadikhah (2013) developed a two-phase Lagrangian CFD model to simulate 3D motion of particles in the gas pipeline elbow with diameter of 56 inches, where the ratio "curvature bend radius-to-pipeline diameter" is 1.5 . It is established that larger particles are moved toward the outer wall of the elbow.

Kuan (2005) used CFD modeling to study two-phase flows in the duct elbow with diameter of $500 \mathrm{~mm}$. It was found that the rate of fine particles is almost equal to that of the main flow, and large particles are less responsive to local changes in the flow rate in the elbow. Thus, the rate of particles near the convex side of the elbow, where the flow slows down, may greatly exceed the local velocity of gas. Accordingly, a local reduction in the concentration of particles occurs near the concave side of the elbow.

Mohanarangam et al. (2008) used Eulerian and Lagrangian approaches to model two-phase gas-flows over a square-sectioned elbow. It was found that the Lagrangian approach helps obtain finer details of the behavior of particles, while Eulerian approach can be used for industrial scale problems.

Chu and $\mathrm{Yu}$ (2008) employed computer modeling in studying the movement of discrete phases in complex 3D systems, including pipe elbows with diameter of $40 \mathrm{~mm}$ and cyclone separator. It is shown that the modeling results are in good agreement with the experimental data, and can generate information leading to a better understanding of the internal flow structure of these systems.

Azimian and Bart (2014) employed computer modeling in studying the motion of solid particles in the elbow and T-junctions of a pipeline with diameter of $25 \mathrm{~mm}$. Research was performed for different flow rates at the inlet, different solids concentration, particle size and shape. It is established that the erosion in the T-junction, where the entire flow goes into the branch of the T-junction, is greater than at the outlets.

Upon impact, the reflected velocity of the particle is lower than the incoming velocity due to energy transfer. Energy is dissipated as heat, noise and target material deformation. This impact signature is described by the momentum based coefficient of restitution. The CFD code originally assumes that the impact signature can be adequately described through consideration of the normal velocity component alone, and that the coefficient is angle insensitive (Forder et al. 1998).

Despite the considerable efforts applied to the study of the gas flow in pipelines, the movement of multiphase flows in elbows and T-junctions of gas mains has not been studied yet. Along with experimental laboratory research into the movement of flow in the transparent elbows and T-junctions, attempts are made to build a physical picture of the flow of these elements in gas mains. However, the physical picture of multiphase flow in elbows and Tjunctions of gas mains is complex and ambiguous, and it is quite difficult to calculate it in theory, and experiments cannot be carried out in real conditions of gas mains.

The objective of the research is to develop methods to study the dynamics of the movement of multiphase flows of gas in elbows and T-junctions of the linear part of the gas main. We also performed a detailed study of regularities in the movement of multiphase flows in elbows and T-junctions, as well as the trajectory of the particles of discrete phase, places of intensive collision of liquid and solid particles carried by the flow with the pipe wall, and impact angles, diameter, velocity of particles in elbows and T-junctions.

Hot bend elbows have L-, Z- and U-shaped compensators of above-ground crossings of pipelines. They are also present in places of abrupt breakings of terrain and pipeline route turns. In elbows of $\mathrm{L}$ - and U-shaped compensators, the product flow changes its direction by $90^{\circ}$, and in elbows of Z-shaped compensators, the flow changes direction by $60^{\circ}$ (Figure 1a). In T-junctions at the beginning of each branch of the gas main, gas moves in the Tjunctions run-pipe, and part of flow goes into the branch (Figure 1b). 


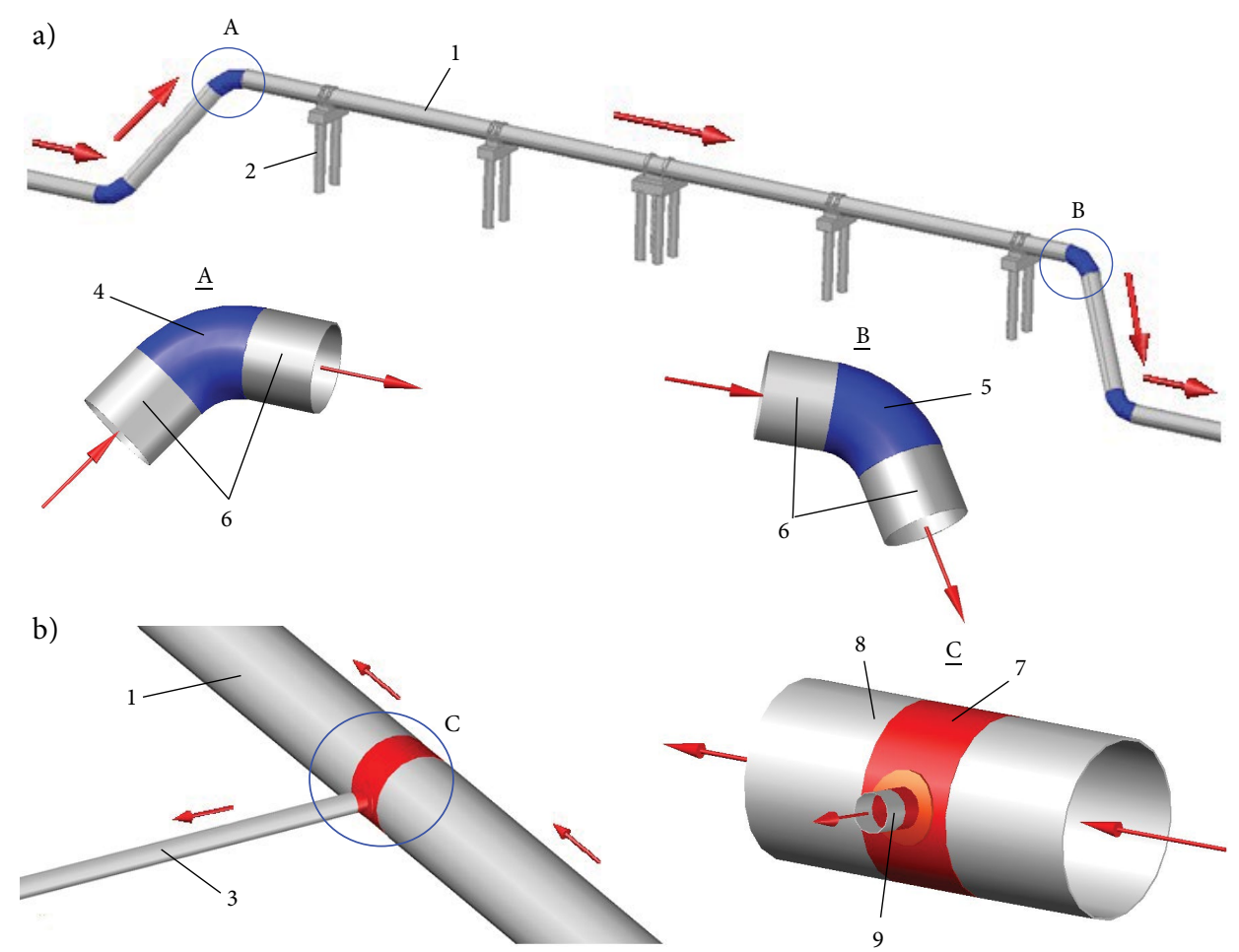

Figure 1. The locations of elbows and T-junction: $\mathrm{a}$ - above-ground crossing; $\mathrm{b}$ - branch from the main; 1 - gas main; 2 - support; 3 - branch; 4,5 - elbow $60^{\circ} 1420 \times 28 \mathrm{~mm} ; 6$ - pipe $1420 \times 21.5 \mathrm{~mm} ; 7$-T-junction welded with reinforcing plate $1420 \times 20 \ldots 325 \times 9 \mathrm{~mm} ; 8-$ pipe $1420 \times 18.7 \mathrm{~mm} ; 9$-pipe $325 \times 8 \mathrm{~mm}$

It is known that natural gas transported in gas mains contains liquid and solid particles (impurities). The fluid discrete phase includes gas condensate, water, lubricant and other hydrocarbons. The solid discrete phase includes rock carried from deposit wells, sand, slag exfoliated from the inner wall of the pipe, and the products of inner pipe corrosion.

The reasons for the presence of such impurities in the inner cavity of pipelines are different. First is the poor quality of gas cleaning in the gas production and compressor stations, condensing of fluid from the gas flow at favorable thermodynamic conditions while pumping gas in the pipeline, passing of bearing lubrication from pumps of gas pumping units, poor cleaning of the inner cavity of the pipeline before putting it into operation, and so on. Chemical reaction between the pipe metal and liquid impurities accumulated in the bottom part of the pipelines leads to the inner pipe corrosion and formation of solid particles.

The presence of discrete phase in the inner cavity of gas pipelines, passing of liquid particles from the bottom sections of the route with gas flow leads to the formation of multiphase flows, which in their turn cause erosive wear in shaped elements of gas mains. Multiphase flows are those which consist of the continuous phase (natural gas) and distributed therein discrete phase (liquid and solid particles). Multiphase flows have far more complex physics than single-phase ones. There may be significantly different modes of multiphase flow: drip, bubble, slug and foam. In addition, there is not a single universal model for simulation of all possible modes. Moreover, there exist quite different approaches to simulation of different modes.

To predict erosive wear in elbows and T-junctions of the linear part of the gas main, one should know the places of intensive collisions of particles with the wall, the velocity of discrete phases in elbows and T-junctions, and impact angles. One can investigate the dynamics of multiphase flows in elbows and T-junctions with computer modeling of 3D turbulent flows using software system ANSYS Fluent R17.0 Academic. Mathematical models and numerical algorithms laid in this system meet the international standards.

ANSYS Fluent R17.0 Academic software system can model:

- gas movement in elbows and T-junctions of gas pipelines;

- movement of multiphase flows in elbows and T-junctions of gas pipelines;

- erosive wear of elbows and T-junctions of gas pipelines.

To simulate multiphase flows in ANSYS Fluent R17.0 Academic, both Euler and Lagrange approaches are employed.

Euler's approach considers changes in the parameters of flow (velocity, pressure and temperature) as points in space. For multiphase flows, a new quantity is introduced: a phase volume fraction, which is another parameter of the flow. Within Euler's approach, all phases are seen as continuous, regardless of their actual morphology. 
The basis of the Lagrangian approach is studying the motion of individual particles (or groups of particles) of the discrete phase.

Lagrangian Discrete Phase Model (DPM) makes it possible to build the trajectory of the particles motion in the continuous phase through solving differential equations of particles motion. The discrete phase can be both solid and not solid, featuring bubbles in fluid or droplets in gas. The model allows for two-way exchange of mass, momentum and energy of the particles with continuous phase. DPM is used for small values of volume concentration of particles because the interaction of particles with each other is taken into account indirectly. The advantage of DPM is that it allows for the accurate determination of interaction nature between the discrete phase and the wall. In the model framework of interaction between the discrete phases and the wall, there is an additional model of wall erosion. In addition, the DPM framework makes it easier to regard the secondary decay of discrete phase (if these are droplets or bubbles). The disadvantage of the DPM is its limitation on a local volume concentration of particles (less than 10\%).

To simulate the motion dynamics of multiphase flow in elbows and $\mathrm{T}$-junctions of the linear part of gas pipeline, the Lagrangian DPM was chosen because it makes it possible to build the trajectory of the particles motion of discrete phase in the continuous phase, determine the velocity of the particles motion, which is necessary for finding the intensive collision by liquid and solid particles, carried by the flow of natural gas, to the pipe wall, impact angles in place of collision that are necessary for a detailed examination of erosive wear in the pipes of gas pipelines. In addition, the Lagrangian DPM allows for the accurate determination of interaction nature between the discrete phase particles and the wall; in the framework of interaction between the particles and the wall, there is an additional model of wall erosion, where the volume concentration of discrete phase in natural gas is less than $10 \%$.

The flow of natural gas of the continuous phase is modeled in ANSYS Fluent by numerical solution of a set of equations describing the broadest case of gaseous medium movement. These are the Navier-Stokes equation (1), which expresses the law of conservation of momentum (or Reynolds (2) if the flow is turbulent), and the equation of continuity (3), which expresses the law of mass conservation:

$$
\begin{aligned}
& \frac{\partial}{\partial t}\left(\rho \cdot u_{i}\right)+\frac{\partial}{\partial x_{j}}\left(\rho \cdot u_{i} \cdot u_{j}\right)= \\
& -\frac{\partial p}{\partial x_{i}}+\frac{\partial}{\partial x_{j}}\left(\mu \cdot\left(\frac{\partial u_{i}}{\partial x_{j}}+\frac{\partial u_{j}}{\partial x_{i}}\right)\right)+f_{i} ; \\
& \frac{\partial}{\partial t}\left(\rho \cdot \bar{u}_{i}\right)+\frac{\partial}{\partial x_{j}}\left(\rho \cdot \bar{u}_{i} \cdot \bar{u}_{j}\right)+\frac{\partial}{\partial x_{j}}\left(\rho \cdot \bar{u}_{i}^{\prime} \cdot \bar{u}_{j}^{\prime}\right)= \\
& -\frac{\partial p}{\partial x_{i}}+\frac{\partial}{\partial x_{j}}\left(\mu \cdot\left(\frac{\partial \bar{u}_{i}}{\partial x_{j}}+\frac{\partial \bar{u}_{j}}{\partial x_{i}}\right)\right)+f_{i} ;
\end{aligned}
$$

$$
\frac{\partial \rho}{\partial t}+\frac{\partial}{\partial x_{j}}\left(\rho \cdot u_{j}\right)=0,
$$

where: $x_{i}, x_{j}$ - coordinates; $t$ - time; $u_{i}, u_{j}$ - velocity components; $\rho$ - density of gas; $\mu$ - molecular dynamic viscosity of the gas; $f_{i}$ - a term that takes into account the effect of mass forces; $p$ - pressure; $\bar{u}_{i}, \bar{u}_{j}$ - the average time values of velocities; $\bar{u}_{i}^{\prime}, \bar{u}_{j}^{\prime}$ - pulsative velocity components (Squires, Eaton 1990).

As a rule, boundary conditions are the conditions of adhesion on all solid walls (the flow rate is zero), which also include the distribution of all velocity components in the inlet section, and the equality to zero of the first derivative (in the direction of flow) of the velocity component in the outlet section. Pressure is presented only in the form of the first derivative, therefore, it is necessary to specify pressure only at any one point of the calculated geometry.

For closure of those equations in ANSYS Fluent R17.0 Academic, $k-\varepsilon$ two-parameter turbulence model was applied ( $k$ - turbulent energy; $\varepsilon$ - the rate of dissipation of turbulent energy), which involves solving of the following equations:

- equation of transfer of turbulent energy $k$ :

$$
\begin{aligned}
& \frac{\partial(\rho \cdot k)}{\partial t}+\nabla(\rho \cdot u \cdot k)= \\
& \nabla\left(\left(\mu+\frac{\mu_{t}}{\sigma_{k}}\right) \cdot \nabla k\right)+\mu_{t} \cdot G-\rho \cdot \varepsilon ;
\end{aligned}
$$

- equation of transfer of turbulent dissipation $\varepsilon$ :

$$
\begin{aligned}
& \frac{\partial(\rho \cdot \varepsilon)}{\partial t}+\nabla(\rho \cdot u \cdot \varepsilon)= \\
& \nabla\left(\left(\mu+\frac{\mu_{t}}{\sigma_{\varepsilon}}\right) \cdot \nabla \varepsilon\right)+C_{1} \cdot \frac{\varepsilon}{k} \cdot \mu_{t} \cdot G-C_{2} \cdot \rho \cdot \frac{\varepsilon^{2}}{k},
\end{aligned}
$$

where: $u$ - flow rate of gas; $\mu_{t}$ - turbulent dynamic viscosity of gas; $\sigma_{k}$ - coefficient equal to one; $G$ - design variable; $\sigma_{\varepsilon}-$ coefficient $\left(\sigma_{\varepsilon}=1.3\right) ; C_{1}-$ coefficient $\left(C_{1}=\right.$ 1.44); $C_{2}-$ coefficient $\left(C_{2}=1.92\right)$.

Turbulence model $k-\varepsilon$ is the so-called "High Reynold Model" (Reynold-averaged Navies-Stokes) - a model created on the basis of averaging Navier-Stokes and designed to compute turbulent processes.

The substance, which is present in the flow of the continuous phase in the form of the discrete phase, does not form a continuum, and some particles interact with the flow of continuous phase and with each other. For modeling of discrete phase in continuous phase in ANSYS Fluent R17.0 Academic, Lagrangian approach is used, i.e. the motion of individual particles caused by the forces of the flow of continuous phase is tracked.

It is believed that the particles of discrete phase are spherical. The forces acting on the particle are due to difference between particle velocity and flow velocity of the continuous phase, and the extrusion by this particle of the medium from the continuous phase. The equations of 
motion of such a particle was derived by Squires, Eaton (1990) and has the form:

$$
\begin{aligned}
& m_{p} \frac{d u_{p}}{d t}=3 \cdot \pi \cdot \mu \cdot d_{p} \cdot C_{c o r} \cdot\left(u-u_{p}\right)+ \\
& \frac{\pi \cdot d_{p}^{3} \cdot \rho}{6} \frac{d u}{d t}+\frac{\pi \cdot d_{p}^{3} \cdot \rho}{12}\left(\frac{d u}{d t}-\frac{d u_{p}}{d t}\right)+ \\
& F_{e}-\frac{\pi \cdot d_{p}^{3}}{6} \cdot\left(\rho_{p}-\rho\right) \cdot \vec{\omega} \times(\vec{\omega} \times \vec{r})- \\
& \frac{\pi \cdot d^{3} \cdot \rho_{p}}{3} \cdot\left(\vec{\omega} \times u_{p}\right),
\end{aligned}
$$

where: $m_{p}$ - particle's mass; $u_{p}$ - velocity of particle motion; $d_{p}$ - diameter of the particle; $C_{c o r}$ - coefficient of viscous resistance; $F_{e}$ - external force that acts directly on the particle (such as gravity or strength of the electric field); $\vec{\omega}$ - angular velocity of rotation; $\vec{r}$ - radius vector (in case of considering motion in the relative frame of reference).

The right side of Equation (6) is the sum of all forces acting on the particle, expressed in terms of mass and acceleration of the particle. The first term on the right side is the inhibition of the particle as a result of viscous friction to flow of the continuous phase according to Stokes' law. The second term is the force applied to the particle, which is caused by the accelerated flow of the continuous phase caused by the pressure drop in the continuous phase surrounding the particle. The third term is the force required to accelerate weight of the continous phase volume extruded by the particle. These two terms should be considered, because the main phase density exceeds the density of particles. The fourth term $\left(F_{e}\right)$ is external force that acts directly on the particle, such as gravity, which was included in the calculation. The last two terms are the centrifugal force and the Coriolis force, which take place only if the motion is regarded within the relative frame of reference. In addition, sometimes in the right side of Equation (6) one should consider some additional forces (e.g. in the event of a significant temperature difference in the flow).

Equation (6) is a differential equation of the first order, in which the only unknown value is the velocity of particle $u_{p}$, and the argument is time $t$. The flow velocity of the continuous phase $u$ at all points of space is considered as known and defined by solution of Equations (1), (2) and (3). Initial data in addition to the size and properties of the particle include its position at the initial time. It is also indicated what will occur when the particle collides with the wall or other particle. To perform the calculation, terms that have $u_{p}$ are moved to the left side of Equation (6). The velocity and location of the particle in each successive time are determined by numerical integration of the time with a certain step $\Delta t$ of all other terms of the Equation (6).

The algorithms implemented in ANSYS Fluent R17.0 Academic make it possible to simulate the impact of the discrete phase on the flow of the continuous phase. In the first approximation, the density and viscosity of the continuous phase and some other values are multiplied by $\left(1-\alpha_{p}\right)$, where $\alpha_{p}$ - the specific volume occupied by particles. Then, at every step of time, changes are calculated as to the mass, momentum and energy of the particles, and these changes are added accordingly to the Equations of conservation of mass (2), pulse (1) and the flow energy of the continuous phase. Thus, the calculation of the continuous phase flow and the calculation of particles motion are made simultaneously.

Modern software products implement several boundary conditions that correspond to different events that occur in case of the particle collision to the wall: reflection as a result of elastic or inelastic impact, sticking to the wall, sliding along the wall (depending on the physical properties and the impact angle), passing through wall (if the wall is porous), and others. Under certain conditions, there is also a possibility of modeling splitting and merging of water droplets or gas bubbles when they collide with each other (Usachyov et al. 2009). 3D models of elbow and T-junction of the linear part of gas mains, the design and geometric dimensions of which are identical to industrial designs (Figure 1), have been drawn in a geometric module ANSYS Fluent R17.0 Academic - Design Modeler. Elbow and T-junction were drawn with the adjacent sections of pipes, whose geometric dimensions meet specifications. In preprocessor Fluent - Meshing, the volume calculation grid automatic was generated, and the volume was filled with triangular prisms. The size of mesh elements was $0.1 \mathrm{~m}$ (Figure 2). To better describe the near-boundary layer, there was created a near-wall layer of lattices called "inflation" with 5 lattices (Figure 2). For such a size of mesh elements, the calculation results were qualitatively visualized, and the calculation time was about one hour.
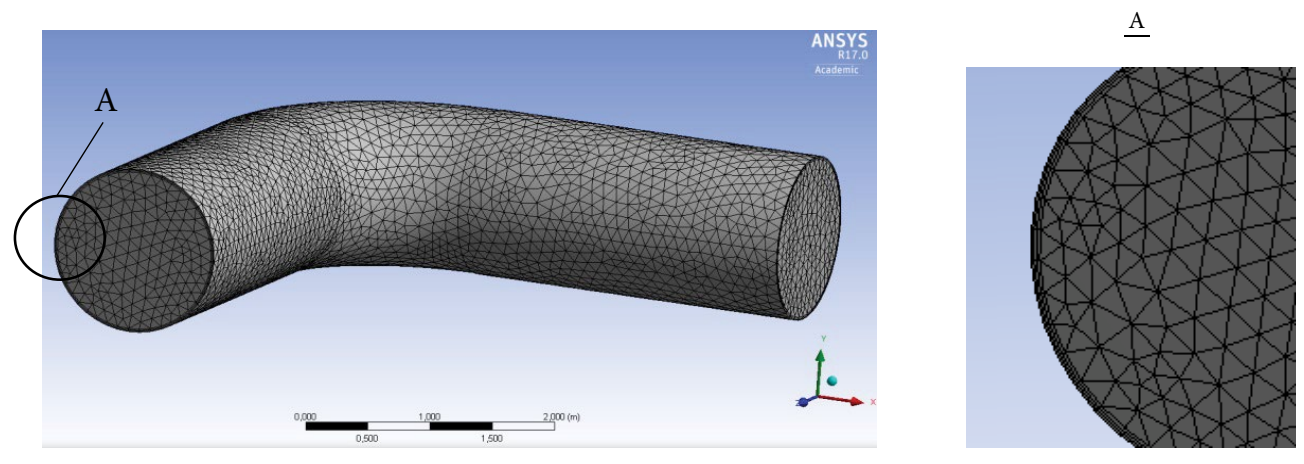

Figure 2. The volume calculation grid 
Velocity and temperature of particles of the discrete phase at the inlet of elbow and T-junction were assumed equal to the velocity and temperature of the continuous phase at the inlet. The velocity of the contiuous phase at the inlet of a shaped element was determined by calculation of the gas dynamics of the linear part of the elbow and T-junction in ANSYS Fluent R17.0 Academic without taking into accout the presence of the discrete phase in the flow (Doroshenko et al. 2016). The temperature of the continuous phase corresponds to the operating conditions of the gas mains. Moisture content of natural gas depends on the temperature and pressure of gas and it is determined by nomogram given in (Kotlyar, Piljak 1971). Based on moisture content of natural gas and volume flow of the continuous phase, mass flow of the fluid phase was calculated.

According to the Standard GOST 5542-87, the mass of mechanical impurities contained in natural gas must not exceed $0.001 \mathrm{~g} / \mathrm{m}^{3}$. According to (Usachyov et al. 2009), natural gas that is put into gas distribution stations contains much more impurities than $0.001 \mathrm{~g} / \mathrm{m}^{3}$. Sinajskij et al. (2002) is stated that the mass of mechanical impurities in natural gas may be up to $0.003 \mathrm{~g} / \mathrm{m}^{3}$. The mass of impurities in natural gas was assumed to be equal to $0.003 \mathrm{~g} / \mathrm{m}^{3}$. The mass flow of the solid phase was calculated taking into account the mass of impurities in natural gas and the volume flow of the continuous phase.

The maximum diameter of droplets of the fluid phase according to Sinajskij et al. (2002) is equal to:

$$
d_{\text {cond }}^{\max }=2 \cdot D_{\text {in }} \cdot k_{f}^{-\frac{3}{5}} \cdot W e^{-\frac{3}{5}} \cdot\left(\frac{\rho_{g}}{\rho_{f}}\right)^{\frac{2}{5}},
$$

where: $D_{\text {in }}$ - inner diameter of the gas pipeline; $k_{f}$ - drag coefficient of a droplet $\left(k_{f}=0.4\right) ; \rho_{g}$ - density of gas; $\rho_{f}-$ density of the fluid phase; We - Weber number (dimensionless parameter).

$$
W e=\frac{\rho_{g} \cdot u^{2} \cdot D_{i n}}{\Sigma},
$$

where: $\Sigma$ - strength of surface tension of the fluid phase on the brink of gas.

The strength of the surface tension of the fluid phase on the brink of gas depends on the pressure and temperature of gas, and it was determined by Gimatudinov et al. (1971).

The maximum diameter of particles of the solid phase was assumed as equal to the size of grains of fine sand.

Since the predominant pollutants contained in the transported natural gas include condensate, water and sand, we chose condensate density $\rho_{\text {cond }}=960 \mathrm{~kg} / \mathrm{m}^{3}$ for the fluid phase, because it is approximately equal to the density of water, and for solid particles we chose sand with density $\rho_{\text {sand }}=2800 \mathrm{~kg} / \mathrm{m}^{3}$.

The reflect condition was specified for the particles at the wall.

The simulation results were visualized in postprocessors ANSYS Fluent R17.0 Academic, ANSYS CFD-Post
R17.0 Academic, which helped investigate and gather comprehensive data on the motion of condensed droplets and solid particles in elbow and T-junction of the linear part of the gas main. We visualized the calculated trajectories of motion of condensed droplets and solid particles in the flow of natural gas, which were then painted in colors that match the velocity and the diameter of the droplets and particles according to the scale of values.

Let us consider the section of above-ground crossing of the gas main at the installation site of elbow 4 with the rotation angle of $60^{\circ}$ (Figure 1). The outer diameter of the elbow is $D_{\text {out.e }}=1420 \mathrm{~mm}$, nominal wall thickness of the bend is $\delta_{N . e}=28 \mathrm{~mm}$. The elbow geometry corresponded to the Technical Specification GazTU 102-488/1-05. The elbow was drawn with adjacent sections of the pipeline $15 \mathrm{~m}$ in length and outer diameter $D_{\text {out }}=1420 \mathrm{~mm}$. Pipe wall thickness was calculated, and then pipes of nominal thickness $\delta_{N}=21.5 \mathrm{~mm}$ were selected from the technical specifications. The inner diameter of the pipes is $D_{\text {in }}=$ $1377 \mathrm{~mm}$ and it is equal to the hydraulic diameter, which was set in ANSYS Fluent R17.0 Academic.

To study the dynamics of multiphase flows in elbow 4 of the above-ground crossing (Figure 1), we set boundary conditions and characteristics of each discrete phase in the ANSYS Fluent R17.0 Academic preprocessor, which are listed in Table 1 and in Figure 3a.

Table 1. Parameters used in CFD analysis of multiphase flow in the elbow

\begin{tabular}{|l|c|c|c|}
\hline \multicolumn{1}{|c|}{ Type of Fluid } & Gas & $\begin{array}{c}\text { Con- } \\
\text { densed } \\
\text { droplets }\end{array}$ & Sand \\
\hline Mass flow inlet $[\mathrm{kg} / \mathrm{s}]$ & 697.9 & - & - \\
\hline Temperature $[\mathrm{K}]$ & 297.0 & 297.0 & 297 \\
\hline Intensity of turbulence [\%] & 5.0 & - & - \\
\hline Pressure outlet $[\mathrm{MPa}]$ & 5.4 & - & - \\
\hline Density $\left[\mathrm{kg} / \mathrm{m}^{3}\right]$ & - & 960.0 & 2800 \\
\hline Velocity inlet $[\mathrm{m} / \mathrm{s}]$ & - & 12.0 & 12 \\
\hline Maximum particle diameter $[\mathrm{mm}]$ & - & 0.34 & 0.12 \\
\hline Minimum particle diameter $[\mu \mathrm{m}]$ & - & 3.0 & 0.1 \\
\hline
\end{tabular}

As shown in Figure 3, when the gas flow with discrete phases moves in the elbow of the above-ground crossing curved at an angle of $60^{\circ}$, it changes its direction resulting in a complicated pattern of movement. Having examined trajectories of discrete phases movement in the elbow, we found that in the place of turn of the convex side, the bigger part of condensed droplets and solid particles (up to $70 \%)$ moves in a flow of the continuous phase along the lines of the current parallel to the pipe wall, slightly approaching the wall in place of turn without colliding it. The smaller part of condensed droplets and solid particles in place of turn of the elbow moves along the trajectory, whose radius is larger than the radius of the elbow, resulting in condensed droplets and solid particles collision to the elbow wall and the pipe welded to it on the right 
a)

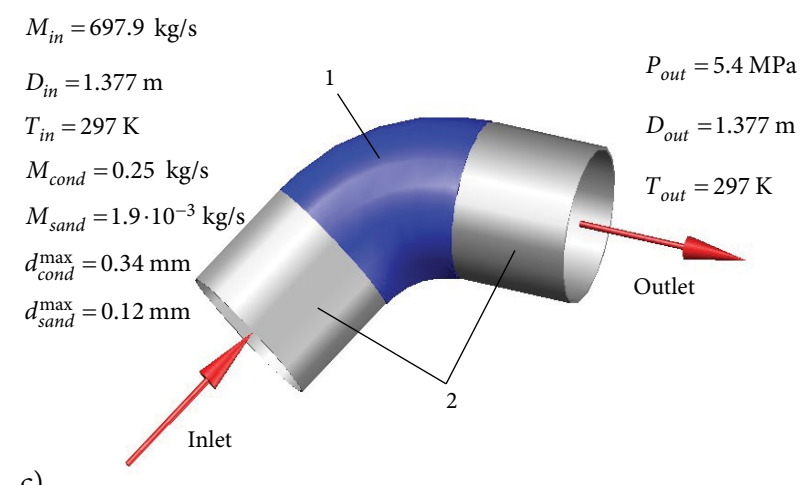

c)

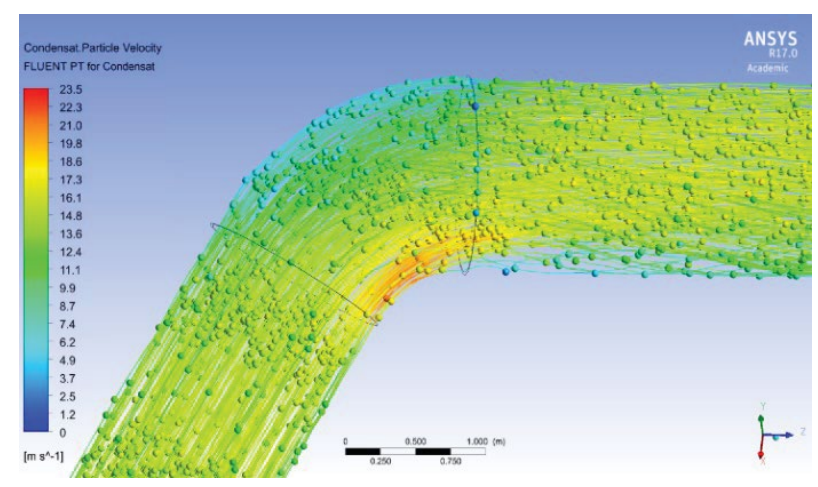

e)

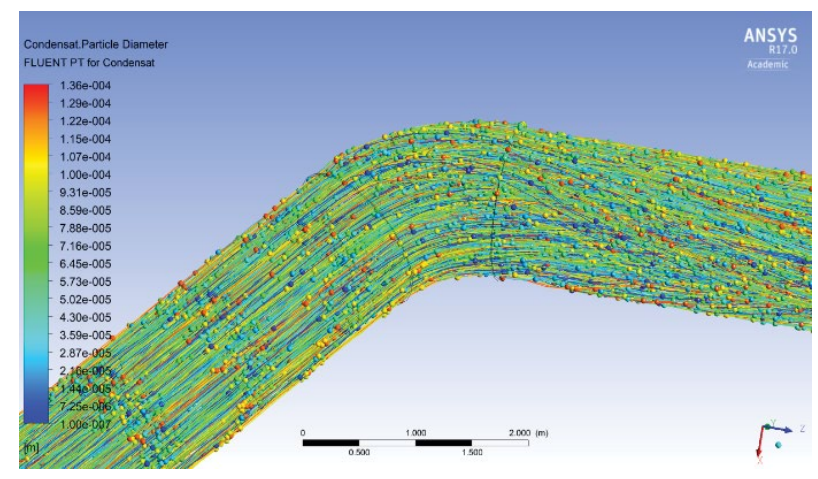

g)

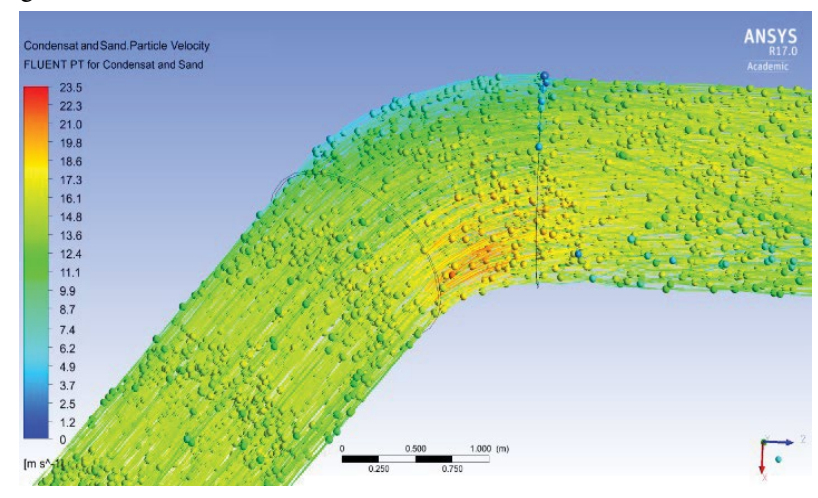

b)

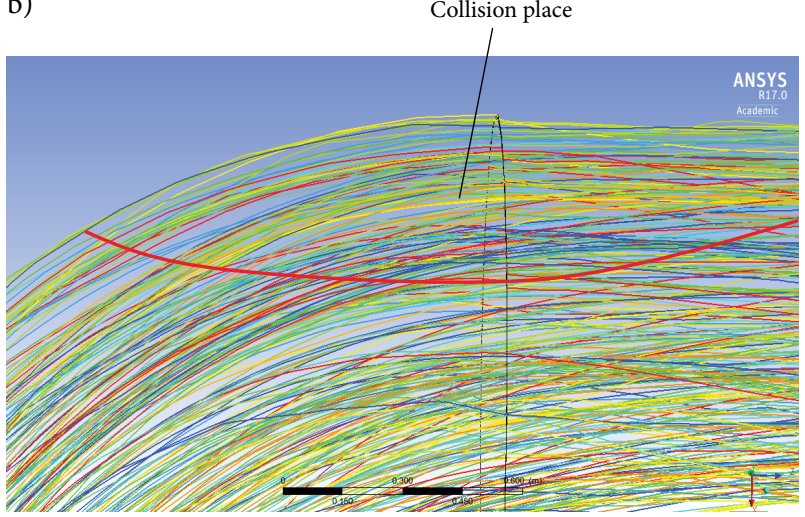

d)

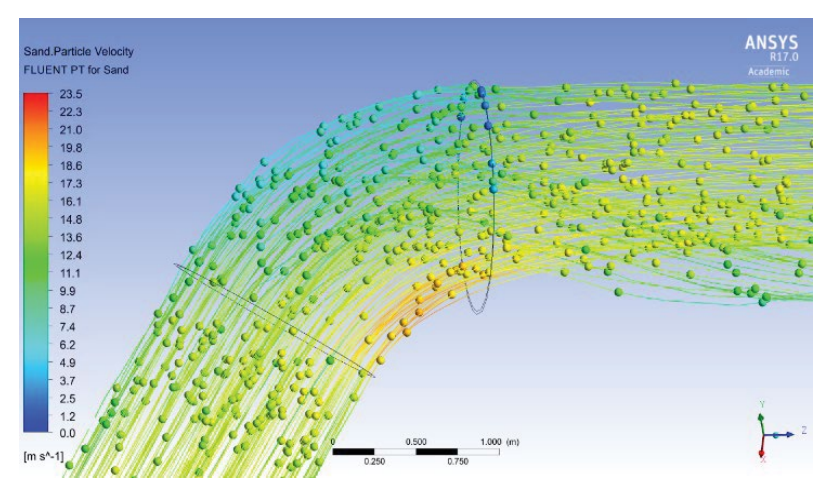

f)

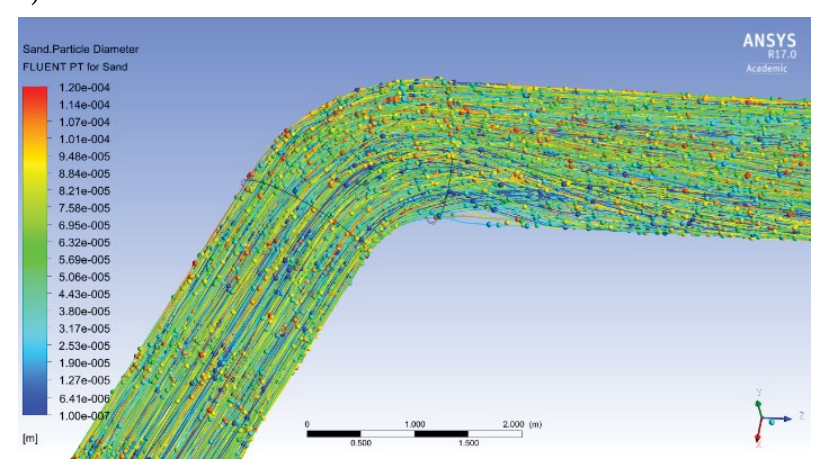

h)

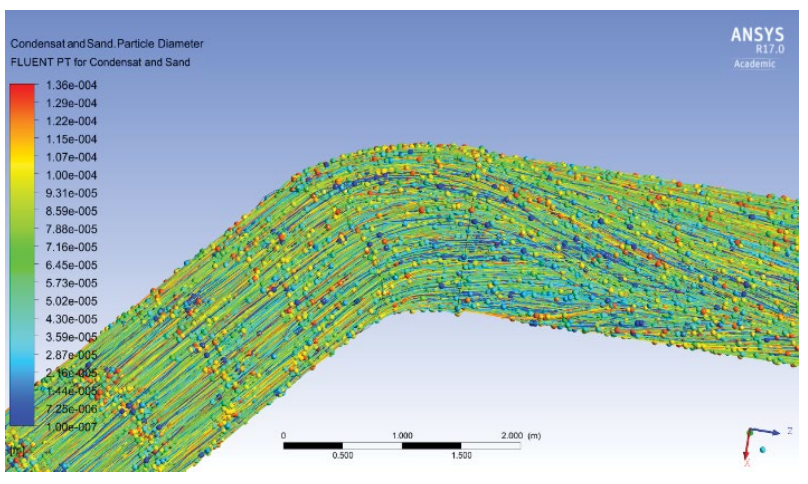

Figure 3. The results of modeling the discrete phase movement in the elbow of above-ground crossing: $1-\mathrm{elbow} 60^{\circ} 1420 \times 28 \mathrm{~mm}$ (Technical Specification GazTU 102-488/1-05); 2 - pipe $1420 \times 21.5 \mathrm{~mm}$; a - calculation scheme; b - trajectory of the discrete phase movement; c - trajectories of motion of condensed droplets painted in colors that match the velocity; $\mathrm{d}$ - trajectories of motion of solid particles painted in colors that match the velocity of particles; e - trajectories of motion of condensed droplets painted in colors that match the diameter of droplets; $\mathrm{f}$ - trajectories of motion of solid particles painted in colors that match the diameter of particles; $\mathrm{g}$ - trajectories of motion of condensed droplets and solid particles painted in colors that match the velocity; $\mathrm{h}$ - trajectories of motion of condensed droplets and solid particles painted in colors that match the the diameter of the droplets and particles 
(Figure 3b). The most intensive collision is in the place of the elbow end on its convex side, and at the beginning of the pipe welded to it. What is more, the farther from the elbow turn, the lower the impact angle is. Therefore, in the end of the elbow it is about $25^{\circ}$, and along the pipe welded to it the angle gradually decreases. The velocity of condensed droplets in the place of collision near the bend end is about $6.2 \mathrm{~m} / \mathrm{s}$, and at the beginning of the welded pipe it reaches $11.5 \mathrm{~m} / \mathrm{s}$ (Figure 3c). The velocity of solid particles is the same in these places (Figure $3 \mathrm{~d}$ ).

In the elbow, the velocity profile of both continuous and discrete phases changes in longitudinal and transverse sections (Figure 3c, 3d, 3g). Along the concave side of the discrete phase it accelerates up to $23 \mathrm{~m} / \mathrm{s}$, and along the convex side it slows down to $5 \mathrm{~m} / \mathrm{s}$. The opposite pattern is observed at the outlet of the elbow - the discrete phase slows down along concave side up to $3 \mathrm{~m} / \mathrm{s}$ and along the convex side, it accelerates to $11.5 \mathrm{~m} / \mathrm{s}$ (Figure 3c, 3d, 3g). At the beginning of turn on the concave side of the elbow, the discrete phases tearing of the pipe wall takes place with increasing distance between the trajectory of the discrete phase and the pipe wall up to $0.08 \mathrm{~m}$. At the outlet of the elbow, a slight turbulence of the gas flow takes place with existing therein-discrete phases, with the discrete phase trajectories approaching the pipe wall.

In addition, an uneven redistribution of discrete phases according to diameter takes place in the elbow (Figure 3e, 3f, 3h). Most condensed droplets and solid particles, which have larger diameters, move along the convex side of the elbow, and some of them collide with the elbow wall and the pipe welded to it, which leads to erosive wear. Discrete phases of smaller diameters move along the concave side of the elbow.

Let us consider the section of the gas main in the place of the branch of the main, where a welded T-junction 7 is set with the reinforcing plate (Figure 1). Gas moves in the T-junction run-pipe, and part of the flow goes to the branch from the run-pipe. The outer diameter of the T-junction run-pipe is $D_{\text {out.r.p }}=1420 \mathrm{~mm}$, the nominal wall thickness is $\delta_{\text {N.r.p }}=20 \mathrm{~mm}$. The outer diameter of the T-junction branch is $D_{\text {out. }}=325 \mathrm{~mm}$, the nominal wall thickness is $\delta_{N . b}=9 \mathrm{~mm}$. T-junction was drawn with adjacent sections of the pipeline $15 \mathrm{~m}$ in length. The pipe wall thickness was calculated, and then pipes with nominal thickness of $18.7 \mathrm{~mm}$ were selected from the technical specifications. Inner diameter of pipes is $1382.6 \mathrm{~mm}$, and it is equal to hydraulic diameter, which was set in ANSYS Fluent R17.0 Academic. Outer diameter of the pipes adjacent to the T-junction branch is $325 \mathrm{~mm}$, nominal wall thickness is $8 \mathrm{~mm}$.

To study the dynamics of multiphase flows in T-junction 7 in a place of the branch (Figure 1), where the gas moves in the T-junction run-pipe, and then part of the flow goes to the T-junction branch, we set boundary conditions in the ANSYS Fluent R17.0 Academic preprocessor along with characteristics of each discrete phase that are listed in Table 2 and Figure $4 \mathrm{a}$.
Table 2. Parametersused in CFD analysis of multiphase flow in the T-junction

\begin{tabular}{|l|c|c|c|}
\hline \multicolumn{1}{|c|}{ Type of Fluid } & Gas & $\begin{array}{c}\text { Con- } \\
\text { densed } \\
\text { droplets }\end{array}$ & Sand \\
\hline Mass flow inlet $[\mathrm{kg} / \mathrm{s}]$ & 697.9 & - & - \\
\hline Particle rate $[\mathrm{kg} / \mathrm{s}]$ & - & 0.25 & 0.0019 \\
\hline Temperature $[\mathrm{K}]$ & 297 & 297 & 297 \\
\hline Intensity of turbulence [\%] & 5.0 & - & - \\
\hline Pressure outlet $1[\mathrm{MPa}]$ & 5.595 & - & - \\
\hline Pressure outlet 2 [MPa] & 5.600 & - & - \\
\hline Density [kg/m $\left.{ }^{3}\right]$ & - & 960 & 2800 \\
\hline Velocity inlet [m/s] & - & 11.6 & 11.6 \\
\hline Maximum particle diameter $[\mathrm{mm}]$ & - & 0.34 & 0.12 \\
\hline Minimum particle diameter $[\mu \mathrm{m}]$ & - & 3.0 & 0.1 \\
\hline
\end{tabular}

To determine the pressure at the outlet of the T-junction branch (Figure 4a), the T-junction for various pressures at the outlet of the T-junction branch was previously calculated in software system ANSYS Fluent R17.0 Academic, then we determined at what pressure at the branch outlet the mass flow is equal to design mass flow. Such pressure was equal to $P_{\text {out } 1}=5.595 \mathrm{MPa}$, and the corresponding mass flow was $M_{\text {out } 1}=27.4 \mathrm{~kg} / \mathrm{s}$.

During the gas flow movement in the T-junction, part of the gas flow with discrete phases changes its direction and passes from the T-junction run-pipe into the branch (mass flow of the T-junction branch is $M_{\text {out } 1}=27.4 \mathrm{~kg} / \mathrm{s}$ ), resulting in a complicated pattern of gas movement in the T-junction (Figure 4). Having studied trajectories of motion of liquid and solid particles in the T-junction, it was found that discrete phases flow in arcuate trajectories from the $\mathrm{T}$-junction run-pipe into the branch, moving in the top of the T-junction run-pipe. What is more, the arcuate trajectories of a small amount of liquid and solid particles come out of the projection boundaries (imaginary contituation) of the T-junction branch into the inner cavity of its run-pipe (Figure 4b). When discrete phases that move along these trajectories approach the wall of the Tjunction run-pipe on the right side of the branch, trajectories of their movement turn round in the direction of gas flow movement in the T-junction run-pipe, and liquid and solid particles collide to the walls of the T-junction run-pipe. The place of collision is the inner surface of the top of the T-junction run-pipe located on the right side of the T-junction branch (Figure $4 \mathrm{~b}$, place of collision 1). The maximum impact angle in the place of collision is observed near the T-junction branch and it is $55^{\circ}$. The farther from the T-junction branch to the right, the smaller the impact angle is. The velocity of condensed droplets in place of collision 1 is from $5 \mathrm{~m} / \mathrm{s}$ to $9 \mathrm{~m} / \mathrm{s}$ (it increases with an increase in the distance from the T-junction branch in the T-junction run-pipe (Figure 4c). The velocity of solid particles is the same at this point (Figure $4 \mathrm{~d}$ ). 
a)
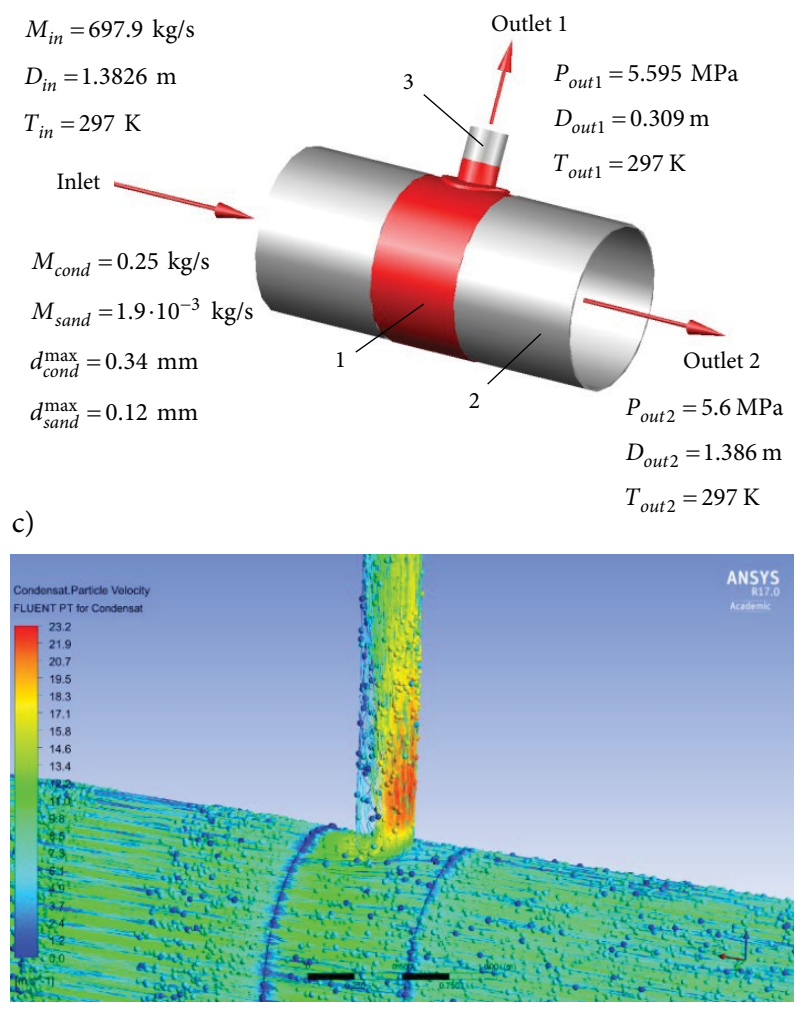

e)

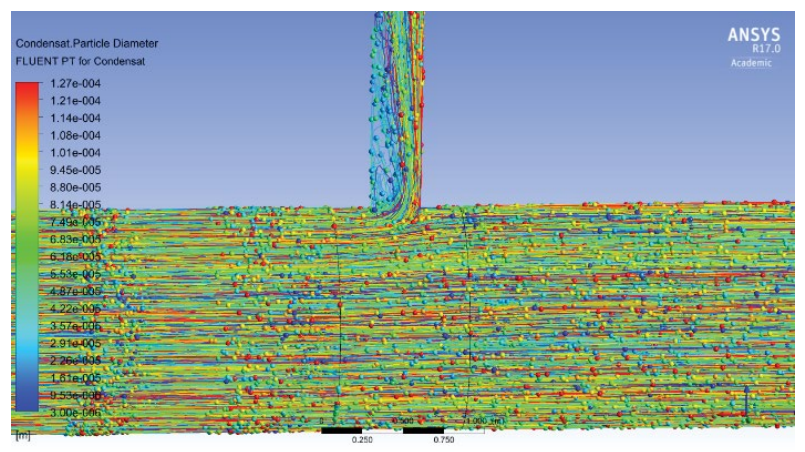

g)

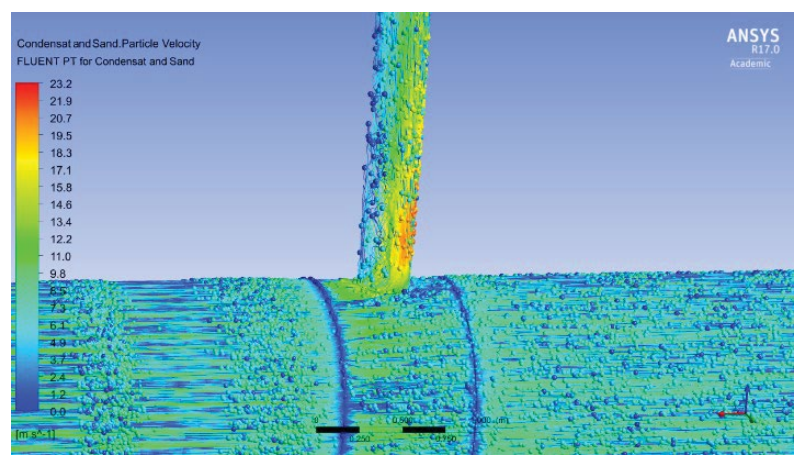

b)

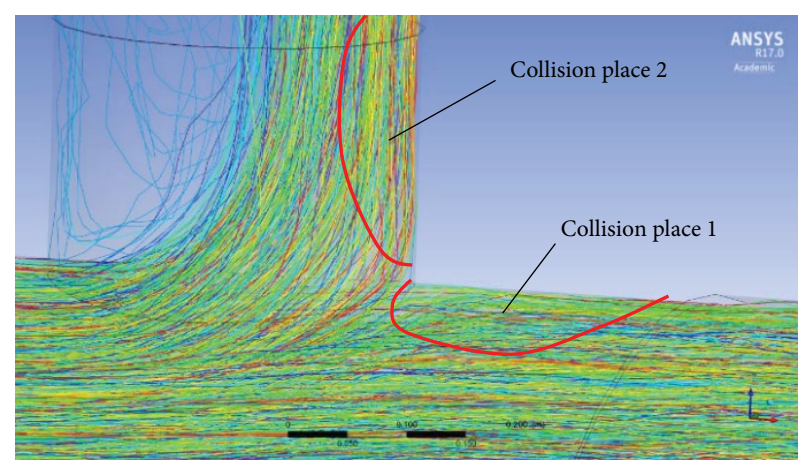

d)

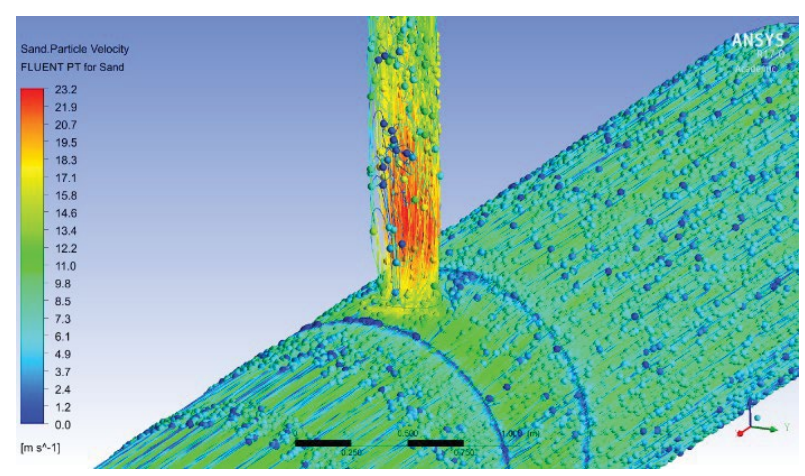

f)

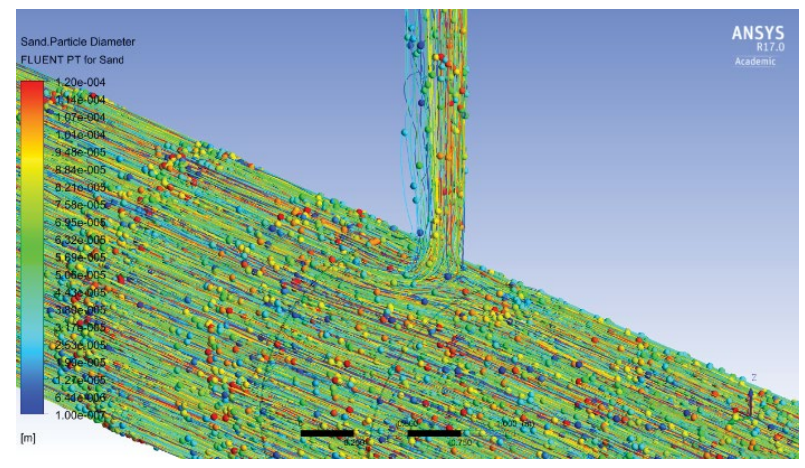

h)

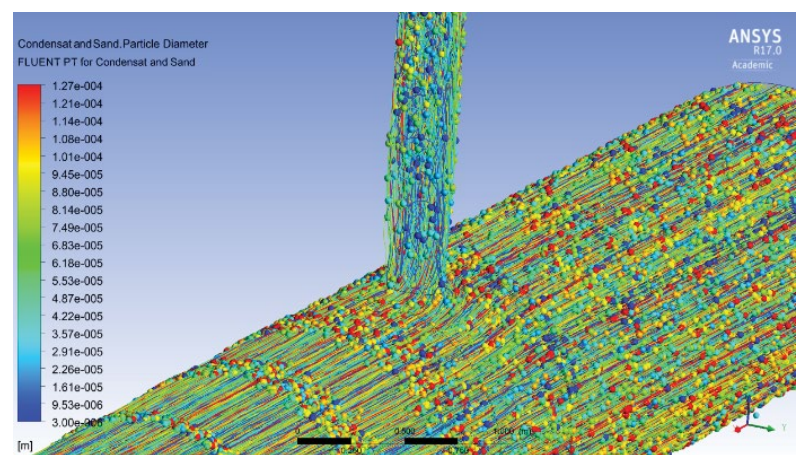

Figure 4. The results of modeling of discrete phases movement in the T-junction located in the place of the branch from the line, where gas moves in the T-junction run-pipe, and part of the flow is directed to the T-junction branch: 1 - welded T-junction with reinforcing plate $1420 \times 20 \ldots 325 \times 9 \mathrm{~mm}$ (Standard OST $102-61-81$ ); 2 - pipe $1420 \times 18.7 \mathrm{~mm} ; 3$ - pipe $325 \times 8 \mathrm{~mm}$; a - calculation scheme; $\mathrm{b}$ - trajectories of discrete phases; $\mathrm{c}$-trajectories of condensed droplets painted in colors that match the velocity; $\mathrm{d}$ - trajectories of solid particles painted in colors that match the velocity of particles; $\mathrm{e}$ - trajectories of condensed droplets painted in colors that match the diameter of droplets; $\mathrm{f}$ - trajectories of solid particles painted in colors that match the diameter of particles; $\mathrm{g}$ - trajectories of discrete phases movement painted in colors that match the velocity; $\mathrm{h}$ - trajectories of discrete phases movement painted in colors that match the diameter of droplets and particles 
Having examined trajectories of discrete phases movement in the T-junction branch, it was found that in the branch, liquid and solid particles that flowed from the T-junction run-pipe, continue to move in arcuate trajectories, resulting in their collision to the wall of the Tjunction branch and the pipe welded to it on the right side (Figure $4 \mathrm{~b}$, place of collision 2 ). The impact angle at the beginning of the bend (at its place of welding to the T-junction run-pipe) is maximum and is about $25^{\circ}$. Next, the impact angle decreases in the branch and the pipe welded to it. The velocity of condensed droplets and solid particles in place of collision at the beginning of the T-junction branch is $6.5 \mathrm{~m} / \mathrm{s}$ and it increases farther from the beginning of the branch and reaches a maximum value of $20 \mathrm{~m} / \mathrm{s}$ at the beginning of the pipe welded to Tjunction branch (Figure 4c, 4d, 4g). At the opposite wall of T-junction of the branch and the pipe welded to it, turbulence of the gas flow with discrete phases takes place (Figure $4 \mathrm{c}, 4 \mathrm{~d}, 4 \mathrm{~g}$ ). The velocity of particles in place of turbulence is from $1 \mathrm{~m} / \mathrm{s}$ to $10 \mathrm{~m} / \mathrm{s}$ (Figure $4 \mathrm{~g}$ ).

It is seen from the visualized simulation results that an uneven redistribution of discrete phases according to the diameter takes place in the T-junction branch (Figure $4 \mathrm{e}, 4 \mathrm{f}, 4 \mathrm{~h})$. Most of condensed droplets and solid particles with larger diameter move in theT-junction branch on its right side and some of them collide to the wall of the branch and the pipe welded to it, which leads to erosive wear (Figure $4 \mathrm{~b}$, place of collision 1). Discrete phases of smaller diameter move at the opposite side of the flow and are contained in the swirling gas flow of the T-junction branch.

\section{Conclusions}

Based on Lagrangian approach and using ANSYS Fluent R17.0 Academic software system, the dynamics of movement of multiphase flows in elbow and T-junction of the linear part of the gas main was investigated for the first time, whose design and geometric dimensions are identical to industrial design.

Calculated trajectories of motion of condensed droplets and solid particles in the flow of natural gas were obtained, which were painted in colors that match their velocity and diameter according to the scale of values that enabled getting a physical picture and collecting comprehensive data on the movement of discrete phases in elbow and $\mathrm{T}$-junction of the linear part of gas main.

The places of heavy collision by condensed droplets and solid particles, carried by the flow of gas, to the pipeline wall, places of swirl of discrete phases, tearing off the flow of liquid and solid particles from the wall of elbow and $\mathrm{T}$-junction were discovered.

The velocity of liquid and solid particles, impact angles, diameters of condensed droplets and solid particles in the place of collision were defined.

Such studies open the prospect for a full and comprehensive research of erosive wear of elbow and T-junction of the linear part of gas mains.

\section{References}

Abdolkarimi, V.; Mohammadikhah, R. 2013. CFD modeling of particulates erosive effect on a commercial scale pipeline bend, ISRN Chemical Engineering 2013: 105912. https://doi.org/10.1155/2013/105912

Azimian, M.; Bart, H.-J. 2014. Investigation of hydroabrasion in slurry pipeline elbows and T-junctions, Journal of Energy and Power Engineering 8(1): 65-78.

https://doi.org/10.17265/1934-8975/2014.01.008

Chu, K. W.; Yu, A. B. 2008. Numerical simulation of complex particle-fluid flows, Powder Technology 179(3): 104-114. https://doi.org/10.1016/j.powtec.2007.06.017

Doroshenko, Ya.; Marko, T.; Doroshenko, Yu. 2016. Doslidzhennya dynamiky ruhu bagatofaznyh potokiv fasonnymy elementamy obv'yazky kompresornoji stanciji magistral'nogo gazoprovodu [Research multiphase flows motion in compressor stations fittings of main gas pipelines], Mizhnarodnyj Naukovyj Zhurnal [International Scientific Journal] 7: 68-77. (in Ukrainian). https://doi.org/10.21267/IN.2016.7.2662

Forder, A.; Thew, M.; Harrison, D. 1998. A numerical investigation of solid particle erosion experienced within oilfield control valves, Wear 216(2): 184-193. https://doi.org/10.1016/S0043-1648(97)00217-2

GazTU 102-488/1-05. Detali soedinitel'nye $i$ uzly dlya magistral'nyh gazoprovodov na $\mathrm{Rr}$ do 9,8 $\mathrm{MPa}$ (100 kgs/kv.sm) (in Russian).

Gimatudinov, Sh. K. 1971. Fizika neftyanogo i gazovogo plasta. Moskva: Nedra. 312 s. (in Russian).

GOST 5542-87. Gazy goryuchie prirodnye dlya promyshlennogo i kommunal'no-bytovogo naznacheniya. Tehnicheskie usloviya (in Russian).

Kotlyar, I. Ya.; Piljak, V. M. 1971. Jekspluataciya magistral'nyh gazoprovodov. Leningrad: Nedra. 248 s. (in Russian).

Kuan, B. T. 2005. CFD simulation of dilute gas-solid two-phase flows with different solid size distributions in a curved $90^{\circ}$ duct bend, Australian and New Zealand Industrial and Applied Mathematics Journal 46: C744-C763.

https://doi.org/10.21914/anziamj.v46i0.988

Lytvynenko, I.; Maruschak, P.; Prentkovskis, O.; Sorochak, A. 2018. Modelling kinetics of dynamic crack propagation in a gas mains pipe as cyclic random process, Lecture Notes in Networks and Systems 36: 262-269.

https://doi.org/10.1007/978-3-319-74454-4_25

Maruschak, P.; Poberezhny, L.; Pyrig, T. 2013. Fatigue and brittle fracture of carbon steel of gas and oil pipelines, Transport 28(3): 270-275. https://doi.org/10.3846/16484142.2013.829782

Maruschak, P.; Bishchak, R.; Prentkovskis, O.; Poberezhnyi, L.; Danyliuk, I.; Garbinčius, G. 2016a. Peculiarities of the static and dynamic failure mechanism of long-term exploited gas pipeline steel, Advances in Mechanical Engineering 8(4): 1-8. https://doi.org/10.1177/1687814016641565

Maruschak, P.; Prentkovskis, O.; Bishchak, R. 2016b. Defectiveness of external and internal surfaces of the main oil and gas pipelines after long-term operation, Journal of Civil Engineering and Management 22(2): 279-286.

https://doi.org/10.3846/13923730.2015.1100672

Maruschak, P.; Danyliuk, I.; Prentkovskis, O.; Bishchak, R.; Pylypenko, A.; Sorochak, A. 2014. Degradation of the main gas pipeline material and mechanisms of its fracture, Journal of Civil Engineering and Management 20(6): 864-872. https://doi.org/10.3846/13923730.2014.971128

Maruschak, P.; Poberezny, L.; Prentkovskis, O.; Bishchak, R.; Sorochak, A.; Baran, D. 2018. Physical and mechanical aspects 
of corrosion damage of distribution gas pipelines after longterm operation, Journal of Failure Analysis and Prevention 18(3): 562-567. https://doi.org/10.1007/s11668-018-0439-Z

Mohanarangam, K.; Tian, Z. F.; Tu, J. Y. 2008. Numerical simulation of turbulent gas-particle flow in a $90^{\circ}$ bend: EulerianEulerian approach, Computers \& Chemical Engineering 32(3): 561-571. https://doi.org/10.1016/j.compchemeng.2007.04.001

OST 102-61-81. Detali magistral'nyh truboprovodov stal'nye privarnye na Ru do 10,0 MPa (100 kgs/sm $\left.{ }^{2}\right)$. Trojniki svarnye s usilivayushhimi nakladkami. Razmery (in Russian).

Panin, S. V.; Maruschak, P. O.; Vlasova, I. V.; Syromyatnikova, A. S.; Bolshakov, A. M.; Berto, F.; Prentkovskis, O.; Ovechkin, B. B. 2017. Effect of operating degradation in arctic conditions on physical and mechanical properties of $09 \mathrm{Mn} 2 \mathrm{Si}$ pipeline steel, Procedia Engineering 178: 597-603. https://doi.org/10.1016/j.proeng.2017.01.117

Poberezhnyi, L.; Maruschak, P.; Prentkovskis, O.; Danyliuk, I.; Pyrig, T.; Brezinová, J. 2016. Fatigue and failure of steel of offshore gas pipeline after the laying operation, Archives of Civil and Mechanical Engineering 16(3): 524-536. https://doi.org/10.1016/j.acme.2016.03.003

Poberezhny, L.; Maruschak, P.; Hrytsanchuk, A.; Poberezhna, L.; Prentkovskis, O; Stanetsky, A. 2017. Impact of gas hydrates and long-term operation on fatigue characteristics of pipeline steels, Procedia Engineering 187: 356-362.

https://doi.org/10.1016/j.proeng.2017.04.386

Sinajskij, Je.; Lapiga, E.; Zajcev, Yu. 2002. Separaciya mnogofaznyh mnogokomponentnyh system. Moskva: Nedra. $622 \mathrm{~s}$. (in Russian).

Squires, K. D.; Eaton, J. K. 1990. Particle response and turbulence modification in isotropic turbulence, Physics of Fluids A: Fluid Dynamics 2(7): 1191-1203. https://doi.org/10.1063/1.857620

Usachyov, A. P.; Shurajc, A. L.; Zhelanov, V. P.; Nedlin, M. S.; Demchuk, V. Ju.; Zubailov, G. I. 2009. Analiz opasnyh sovmestnyh vozdejstvij mehanicheskih chastic i neproporcional'nyh usilij na jelementy gazoreguljatornyh punktov, Nauchno-tehnicheskie problemy sovershenstvovaniya $i$ razvitiya sistem gazojenergosnabzheniya 6: 4-14. (in Russian).

Vilkys, T.; Rudzinskas, V.; Prentkovskis, O.; Tretjakovas, J.; Višniakov, N.; Maruschak, P. 2018. Evaluation of failure pressure for gas pipelines with combined defects, Metals 8(5): 346. https://doi.org/10.3390/met8050346 